\title{
THE TAXONOMY OF BLOOM AND THE ORGANIZATION OF STUDENT LEARNING ACTIVITIES
}

\section{[ТАКСОНОМИЯ БЛУМА И ОРГАНИЗАЦИЯ УЧЕБНОЙ ДЕЯТЕЛЬНОСТИ УЧАЩИХСЯ]}

\section{Aigul Medeshova}

\section{doi: 10.18355/PG.2017.6.2.3}

\begin{abstract}
The article considers the stages of learning materials, methods of cognition as the ultimate goal of learning. The training activities focus on the formation of a personality capable of independent creative activity, responsible for its development and life prospects.
\end{abstract}

\section{Key words}

purpose of education, educational result, Bloom taxonomy, meta-subject activity, self-education

\section{Аннотация}

В статье рассматривается этапы усвоения учебных материалов, способов познания как конечной цели учения. Учебная деятельность направлена на формирования личности, способной к самостоятельной творческой деятельности, ответственная за своё развитие и жизненные перспективы.

\section{Ключевые слова}

цель обучения, образовательный результат, таксономия Блума, метапредметная деятельность, самообучение

\section{Введение}

Образование должно формировать целостную систему знаний, умений и навыков, а также опыт самостоятельной деятельности и личной ответственности обучающихся.

Отличительные для конца XX - начала XXI века изменения в характере образования - в его направленности, целях, содержании все более явно ориентируют его на «свободное развитие человека», на творческую инициативу, самостоятельность обучаемых, конкурентоспособность, мобильность будущих специалистов.

В качестве общего определения такого интегрального социальноличностно-поведенческого феномена как результата образования в совокупности мотивационно-ценностных, когнитивных составляющих и выступило понятие «компетенция/компетентность».

\section{Исследуемый вопрос:}

Каким образом организовать учебной деятельность учащихся в современной школе? 


\section{Методы}

Особое внимание в последнее время уделяется ключевым компетенциям. Этот процесс развивается как под влиянием международных тенденций, так отчасти и независимо от них. В настоящее время не существует общепринятого определение компетенции. Общим для всех определений является понимание ее как способности личности справляться с самыми различными задачами.

В книге «School for the XXI century. Priorities in the reform of education» американский педагог FS Shlehti, ссылаясь на опрос многих бизнесменов, работодателей, школьных функционеров, подчеркивает,что на вопрос "What do you want from school?" («Что вы хотите от школы?») получал, как правило, один и тот же ответ: “We need people who know how to learn independently” («Нам нужны люди, которые умеют учиться самостоятельно»).

По глубокому убеждению FS Shlehti, те школьники, которые освоят успешно базовый курс школьной программы, учатся применять свои знания в знакомой ситуации и даже получат дипломы, но не будут уметь самостоятельно работать с информацией, самостоятельно приобретать знания, не смогут рассчитывать на успех в информационном обществе США XXI века.

"The meaning facilitates learning and makes knowledge useful, since the goals and methods of application are already laid in the understanding”(«Смысл облегчает обучение и делает знание полезным, так как цели и способы применения уже заложены в понимании») (Shepard, 1992). Обучение в современном понимании есть процесс конструирования знания, то есть обучение происходит не через запоминание, а через интерпретацию информации (Fishman, Golub, 2007).

Обучение - это не работа зрителя, пассивного наблюдателя. Цель обучения - развивать потребность учащихся думать, стимулировать обдумывание и анализ того, как они учатся; развивать ответственность самих учащихся за собственное образование. Люди не учатся, просто сидя в аудитории и слушая лектора, вспоминая подготовленные задания и выдавая готовые ответы. Они должны говорить о том, что они изучают и чему научились, писать об этом, связывать это с прошлым опытом и применять изученное в повседневной жизни (Slechty, 1992).

В ходе исторического развития общества и образования как его важнейшего института сложились различные парадигмы образования. Поэтому сегодня можно говорить о том, что существует определенное множество парадигм образования, среди которых наиболее распространена традиционно-консервативная (знаниевая парадигма).

Главной целью знаниевой парадигмы заключается в передаче молодому поколению наиболее существенных элементов культурного наследия человеческой цивилизации и ее опыта. Эта передача осуществляется на основе выдержавшей испытание временем совокупности знаний, умений и навыков, а также нравственных идеалов и жизненных ценностей, способствующих как индивидуальному развитию, так и 
сохранению социального порядка, позволяющих обеспечить функциональную грамотность и социализацию обучающихся.
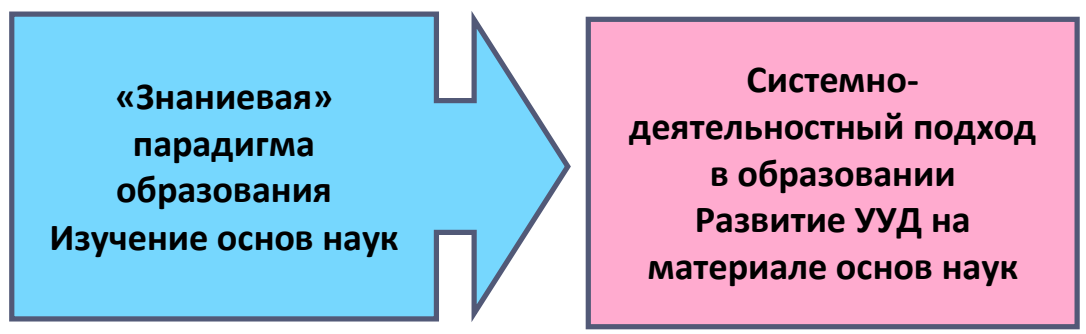

В современном образовательном процессе применяется инновационные технологии. У учащихся формируется не только знание и навыки, а также компетенция. Поэтому важным является деятельностный подход в обучении.

Системно-деятельностный подход обеспечивает:

- формирование готовности к саморазвитию и непрерывному образованию;

- $\quad$ проектирование и конструирование социальной среды развития обучающихся в системе образования;

- активную учебно-познавательную деятельность обучающихся;

- построение образовательного процесса с учётом индивидуальных возрастных, психологических и физиологических особенностей обучающихся

\section{Анализ}

Перспективная система образования должна быть способна не только вооружать знаниями обучающегося, но и, вследствие постоянного и быстрого обновления знаний в нашу эпоху, формировать потребность в непрерывном самостоятельном овладении ими, умения и навыки самообразования, а также самостоятельный и творческий подход к знаниям в течение всей активной жизни человека. Образование должно в итоге стать таким социальным институтом, который был бы способен предоставлять человеку разнообразные наборы образовательных услуг, позволяющих учится непрерывно, обеспечивать широким слоям населения возможность получения послевузовского и дополнительного образования.

В своих работах американский психолог, профессор педагогики Чикагского университета Benjamin Bloom утверждал, что нет плохих учеников, есть плохо обученные ученики. Изучив конкретные показатели психологической готовности учащихся к учебной деятельности, Bloom экспериментально продемонстрировал, что эти показатели обусловлены факторами среды, выделил сенситивные периоды, определяющие формирование познавательных и эмоциональных характеристик готовности к обучению (Fishman, Golub, 2007). 
B. Bloom выделяет шесть категорий целей обучения. (Bloom , Englehart, Furst, Hill, Krathwohl, 1956).

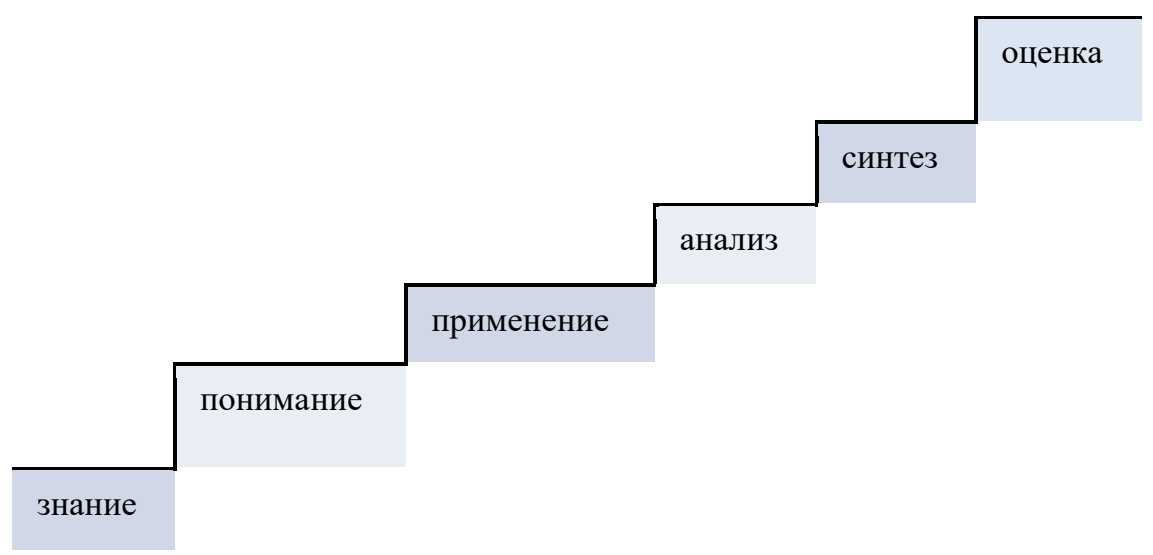

Можно раскрыть таким образом:

\begin{tabular}{|c|c|c|}
\hline Навык & Определение & Ключевые слова \\
\hline Знание & $\begin{array}{l}\text { Припоминание } \\
\text { информации }\end{array}$ & $\begin{array}{l}\text { Определять, описывать, } \\
\text { называть, маркировать, узнавать, } \\
\text { воспроизводить, следовать }\end{array}$ \\
\hline Понимание & $\begin{array}{l}\text { Понимать значение, } \\
\text { перефразировать } \\
\text { главную мысль }\end{array}$ & $\begin{array}{l}\text { Обобщать, } \\
\text { защищать, пеобразовывать, } \\
\text { интерпретировать, } \\
\text { примеры }\end{array}$ \\
\hline Применение & $\begin{array}{l}\text { Использовать } \\
\text { информацию или } \\
\text { концепцию в новой } \\
\text { ситуации }\end{array}$ & $\begin{array}{l}\text { Выстраивать, воздавать, } \\
\text { конструировать, моделировать, } \\
\text { предсказывать, готовить }\end{array}$ \\
\hline Анализ & $\begin{array}{l}\text { Разделять } \\
\text { информацию или } \\
\text { концепции на части } \\
\text { для лучшего } \\
\text { понимания }\end{array}$ & $\begin{array}{l}\text { Сравнить/противопоставить, } \\
\text { разбить, выделить, отобрать, } \\
\text { разграничить }\end{array}$ \\
\hline Синтез & $\begin{array}{l}\text { Соединить идеи для } \\
\text { создания } \\
\text { нового } \\
\end{array}$ & $\begin{array}{l}\text { Группировать, } \\
\text { реконструировать }\end{array}$ \\
\hline Оценка & $\begin{array}{l}\text { Делать суждения } \\
\text { относительно } \\
\text { ценности }\end{array}$ & $\begin{array}{l}\text { Оценивать, критиковать, судить, } \\
\text { оправдывать, } \\
\text { поддерживать }\end{array}$ \\
\hline
\end{tabular}

\section{Применение}


По мнению специалистов "Института информатизации образования" ЮНЕСКО, к наиболее важным направлениям формирования перспективной системы образования можно отнести:

- повышение качества образования путем фундаментализации, применения различных подходов с использованием новых информационных технологий;

- обеспечение опережающего характера всей системы образования, ее нацеленности на проблемы будущей постиндустриальной цивилизации;

обеспечение большей доступности образования для населения планеты путем широкого использования возможностей дистанционного обучения и самообразования с применением информационных и телекоммуникационных технологий (Andreev, 1999).

В ежегодном Послании Президента РК важное место занимают вопросы, связанные с совершенствованием системы образования и науки - это качественный рост человеческого капитала в Казахстане. Президент РК отметил, что в ходе модернизации системы образования нам важно осуществить такие меры, как внедрение в процесс обучения современных методик и технологий, повышение качества педагогического состава, усиление стандартов базового педагогического образования, требований к повышению квалификации преподавателей школ и ВУЗов (Nazarbayev, 2012).

Методы применения

$\checkmark$ Совместная работа сотрудников над документами

$\checkmark$ Совместная проектная работа учащихся

$\checkmark$ Дистанционное обучение

\section{Результаты}

Человек, который способен разрешать нестандартные, значимые для себя ситуации, используя для этого знания, умения, понимания, способности, анализ, опыт и т. д. является компетентным.

Компетентности включают результаты ученика, выражающие «приращение» его знаний, умений, навыков, опыта личностного саморазвития, опыта творческой деятельности, опыта эмоциональноценностных отношений. Ключевые компетентности метапредметны и интегративны по своей природе, так как их источниками являются различные сферы культуры и деятельности (бытовой, образовательной, гражданской, духовной, социальной, информационной, правовой, этической, экологической и др.) (Medeshova, Sumyanova, Amanturlina, 2016).

Включение новых технологий в образовательный процесс, возможность разностороннего проявления творческих способностей современных детей, отказ от репродуктивной формы обучения - все это должно дать новые образовательные результаты. Результаты, которые ранее, например в 1970-е гг., не были востребованы. А сегодняшним выпускникам необходимо умение работать с информацией, быть ИКТкомпетентными. 
К новым образовательным результатам относятся: овладение ключевыми компетенциями, освоение новых умений и навыков по сравнению с существующей практикой, развитие познавательных интересов, развитие информационной культуры, развитие ключевых компетенций (интерактивное использование цифрового учебного оборудования и программных инструментов, работа в группе), освоение умений творчески применять знания в практических ситуациях, сдвиг от поглощения информации к производству знаний и прочее (Malyova, 2013).

Образовательный результат - это индивидуальная способность, знание, умение, навык. В традиционном понимании образовательный результат - это знание, освоенное учащимся на конкретном уровне, который определяется в зависимости от сложности умственных операций, совершаемых обучающимся с этим знанием (Bespalko, 1995).

Метапредметные результаты формируются за счёт реализации программы формирования универсальных учебных действий и программ всех без исключения учебных предметов. Важнейшей задачей современной системы образования является формирование совокупности «универсальных учебных действий», обеспечивающих компетенцию «научить учиться», а не только освоение учащимися конкретных предметных знаний и навыков в рамках отдельных дисциплин.

Достижение метапредметных результатов обеспечивается за счёт основных компонентов образовательного процесса - учебных предметов.

Основным объектом оценки метапредметных результатов служит сформированность у обучающегося регулятивных, коммуникативных и познавательных универсальных действий, т. е. таких умственных действий обучающихся, которые направлены на анализ и управление своей познавательной деятельностью. К ним относятся:

- способность обучающегося принимать и сохранять учебную цель и задачи; самостоятельно преобразовывать практическую задачу в познавательную, умение планировать собственную деятельность в соответствии с поставленной задачей и условиями её реализации и искать средства её осуществления; умение контролировать и оценивать свои действия, вносить коррективы в их выполнение на основе оценки и учёта характера ошибок, проявлять инициативу и самостоятельность в обучении;

- умение осуществлять информационный поиск, сбор и выделение существенной информации из различных информационных источников;

- умение использовать знаково-символические средства для создания моделей изучаемых объектов и процессов, схем решения учебно-познавательных и практических задач;

- способность к осуществлению логических операций сравнения, анализа, обобщения, классификации по родовидовым 
признакам, к установлению аналогий, отнесения к известным понятиям;

- умение сотрудничать с педагогом и сверстниками при решении учебных проблем, принимать на себя ответственность за результаты своих действий.

Общим для всех определений является понимание ее как способности личности справляться с самыми различными задачами.

Carl Rogers выделял следующие основные принципы:

- индивид находится в центре постоянно меняющегося мира. Отсюда следуют два вывода, чрезвычайно важных для педагога: для каждого индивида значим собственный мир восприятия окружающей действительности; этот внутренний мир не может быть до конца познан никем извне;

- человек относится к окружающей действительности сквозь призму собственного восприятия и понимания;

- человек стремится к самопознанию и к самореализации; человек обладает внутренней потребностью к самосовершенствованию;

- взаимопонимание, столь необходимое для развития личности, может достигаться только в результате общения;

- самосовершенствование, развитие происходит на основе взаимодействия со средой, с другими людьми. Внешняя оценка весьма существенна для человека, для его самопознания, что достигается в результате прямых контактов или скрытых.

Многие взгляды C.Rogers легли в основу личностно-ориентированной педагогики (Lefrancois, 1991).

\begin{abstract}
Выводы
Достижение образовательных результатов может проявиться в успешности выполнения комплексных заданий на межпредметной основе. В частности, широкие возможности для оценки сформированности метапредметных результатов открывает использование проверочных заданий, успешное выполнение которых требует освоения навыков работы с информацией.

Преимуществом двух последних способов оценки является то, что предметом измерения становится уровень присвоения обучающимся универсального учебного действия, обнаруживающий себя в том, что действие занимает в структуре учебной деятельности обучающегося место операции, выступая средством, а не целью активности ребёнка.
\end{abstract}

\title{
Bibliographic references
}

SHEPARD, L. 1992. What policy makers who mandate tests should know about the new psychology of intellectual ability and Learning. In Gifford, B. and O' Connor, M. (eds) Changing Assessments: Alternative Views of Aptitude, Achievement and Instruction. London: Kluwer Academic.

FISHMAN, I. S. - GOLUB, G. B. 2007. Formative evaluation of educational results of students: Methodological manual. Samara.

Slechty, P. S. 1990. Schools for the 21st Century. San Francisco. 
BLOOM, B. - ENGLEHART, M. - FURST, E. - HILL, W. KRATHWOHL, D. 1956. Taxonomy of educational objectives: The classification of educational goals. HANDBOOK I: Cognitive domain. New York, Toronto: Longmans, Green.

ANDREEV, A. A. 1999. Didactic bases of distance learning. M: RAO.

NAZARBAYEV, N. 2012. Message of the President of the Republic of Kazakhstan to the people: "Social and Economic Modernization is the main vector of Kazakhstan's development" dated January 27, 2012.

MEDESHOVA, A. - SUMYANOVA, E. - AMANTURLINA, G. 2016. Development of Training Skills in Students as the Precondition for Educational Competencies. In International journal of environmental \& science education, 2016, N. 11-17, p. 9649-9656.

MALYOVA, G. G. 2013. Electronic educational resources of the new generation in the context of distance learning: orientation to new educational results np "teleshkola", Moscow.

BESPALKO, V. P. 1995. Pedagogy and progressive learning technologies. M. Enlightenment.

LEFRANCOIS, R. G. 1991. Psychology For Teaching. 7th edition. USA, 1991

Assoc. prof. Aigul Medeshova, PhD.

V. Utemisov West Kazakhstan State University,

West Kazakhstan, Uralsk, str. Dostyk 160, chancery

09000 Uralsk,

Kazakhstan

medeshovaa@mail.ru 